\title{
Griscelli syndrome-type 2 in twin siblings: case report and update on RAB27A human mutations and gene structure
}

\author{
I.P. Meschede ${ }^{1}$, T.O. Santos ${ }^{1}$, T.C. Izidoro-Toledo ${ }^{1}$, J. Gurgel-Gianetti ${ }^{2}$ and E.M. \\ Espreafico $^{1}$
}

1'Departamento de Biologia Celular e Molecular e Bioagentes Patogênicos, Faculdade de Medicina de Ribeirão Preto, Universidade de São Paulo, Ribeirão Preto, SP, Brasil

${ }^{2}$ Departamento de Pediatria, Universidade Federal de Minas Gerais, Belo Horizonte, MG, Brasil

Correspondence to: E.M. Espreafico, Departamento de Biologia Celular e Molecular e Bioagentes

Patogênicos, FMRP, USP, Av. Bandeirantes, 3900, 14049-900 Ribeirão Preto, SP, Brasil

Fax: +55-16-3633-1786. E-mail: emesprea@fmrp.usp.br

Griscelli syndrome (GS) is a rare autosomal recessive disorder caused by mutation in the MYO5A (GS1, Elejalde), RAB27A (GS2) or $M L P H(G S 3)$ genes. Typical features of all three subtypes of this disease include pigmentary dilution of the hair and skin and silvery-gray hair. Whereas the GS3 phenotype is restricted to the pigmentation dysfunction, GS1 patients also show primary neurological impairment and GS2 patients have severe immunological deficiencies that lead to recurrent infections and hemophagocytic syndrome. We report here the diagnosis of GS2 in 3-year-old twin siblings, with silvery-gray hair, immunodeficiency, hepatosplenomegaly and secondary severe neurological symptoms that culminated in multiple organ failure and death. Light microscopy examination of the hair showed large, irregular clumps of pigments characteristic of GS. A homozygous nonsense mutation, $\mathrm{C}-\mathrm{T}$ transition (c.550C>T), in the coding region of the $R A B 27 A$ gene, which leads to a premature stop codon and prediction of a truncated protein $(\mathrm{R} 184 \mathrm{X})$, was found. In patient mononuclear cells, RAB27A mRNA levels were the same as in cells from the parents, but no protein was detected. In addition to the case report, we also present an updated summary on the exon/intron organization of the human RAB27A gene, a literature review of GS2 cases, and a complete list of the human mutations currently reported in this gene. Finally, we propose a flow chart to guide the early diagnosis of the GS subtypes and Chédiak-Higashi syndrome.

Key words: Griscelli syndrome; RAB27A; Hemophagocytic lymphohistiocytosis; Cerebellitis; Immunodeficiency

Research supported by FAPESP (\#13100-4), CNPq, and Fundação de Apoio ao Ensino, Pesquisa e Assistência do Hospital das Clínicas da Faculdade de Medicina de Ribeirão Preto (FAEPA) to the laboratory of E.M. Espreafico. I.P. Meschede and T.O. Santos were recipients of Master fellowships from CAPES and FAPESP, respectively, and E.M. Espreafico is the recipient of a researcher fellowship from CNPq (\#308715/2005-5).

Received February 25, 2008. Accepted October 9, 2008

\section{Introduction}

Griscelli syndrome (GS) is a fatal autosomal recessive disorder, first described by Griscelli et al. (1) as partial albinism associated with immunodeficiency. It is a rare and not widely known disease, and its clinical features such as silvery-gray hair and immunological dysfunction resemble Chédiak-Higashi syndrome (CHS), an erythrophagocytic lymphohistiocytosis (2). However, light microscopy examination of the scalp hair is an easy way to differentiate these two syndromes. Hair shafts from $\mathrm{CHS}$ patients reveal small regular melanin aggregates, whereas in GS large clumps of pigment irregularly distributed are found $(3,4)$. In addition, electron microscopic examination of a skin biopsy from $\mathrm{CHS}$ patients reveals giant melanosomes in both melanocytes and keratinocytes (2). In contrast, GS patients show melanocytes with a massive accumulation of mature melanosomes with adjacent keratinocytes containing only sparse melanosomes (3).

GS was classified into three different subtypes, all of 
which show similar pigment dilution. In addition to pigment problems, type 1 (GS1 [MIM 214450], Elejalde), caused by mutation in the MYO5A gene, is associated with severe primary neurological impairment such as developmental delay and mental retardation (4). The MYO5A gene encodes the motor protein myosin- $\mathrm{Va}$, which is highly expressed in the brain and plays a very important function in neurons (5-7).

The second type (GS2 [MIM 607624]), caused by mutation in $R A B 27 A$ gene $(8,9)$, is associated with a primary immunodeficiency due to an impairment of $\mathrm{T}$ cell and natural killer cytotoxic activity, which leads to susceptibility to repeated infections, and culminates in a life-threatening condition known as hemophagocytic syndrome or hemophagocytic lymphohistiocytosis $(\mathrm{HLH})$, usually triggered by viruses and marked by periods of fever, hepatosplenomegaly and pancytopenia. HLH has been characterized by an unremitting polyclonal CD8 ${ }^{+} \mathrm{T}$-cell expansion, and lymphocytic infiltration of visceral tissues that leads to macrophage activation (hemophagocytosis) and the deleterious release of several cytokines, including interferon $\gamma$, interleukins (IL-1, IL-6, IL-18) and tumor necrosis factor- $\alpha$, which sustains the macrophage activation and leads to hyperinflammation, involving progressive deterioration of the central nervous system, and multiple organ failure (1013). RAB27A gene encodes the small GTPase protein Rab27a, which is required for peripheral anchorage of melanosomes in melanocytes, as well as exocytosis of cytolytic granules in cytotoxic $\mathrm{T}$ lymphocytes and natural killer cells or secretory vesicles in endocrine cells $(11,12,14-$ 17).

The third type (GS3 [MIM 609227]), caused by mutation in the melanophilin gene $(M L P H)$, is restricted to hypopigmentation defects (18). Another mutation whose phenotype is restricted to the pigmentation defect is the specific deletion of the MYO5A exon $\mathrm{F}$ (18). The pigment dilution common to GS1, GS2 and GS3 is due to the absolute requirement for these three proteins, myosin-Va, Rab27a and melanophilin, which together form a heterotrimeric protein complex, in melanosome transport $(14,19)$. Thus, a defect in any one of these proteins leads to the same pigmentary defect. In contrast, Rab27a appears to use other molecules, such as the recently uncovered Munc13-4 [FHL3 (MIN 608898)] as effector in cytotoxic-Tlymphocytes and natural killer cells for the exocytosis of lytic granules (20).

\section{Case Report}

This research was part of a project approved by the Human Research Ethics Committee of our institution.
The patients were identical twins (Figure 1A), the first children of a non-consanguineous marriage born to healthy parents after an uncomplicated pregnancy and delivery. The children had normal neuropsychomotor development during the first year of age. At three years of age, one of them was hospitalized with symptoms of encephalitis, confirmed by the presence of a hypersignal in the periventricular white matter of the brain by magnetic resonance imaging (MRI, data not shown), and died abruptly. About nine months later, his twin brother presented fever associated with axial and appendicular ataxia and was admitted to the hospital with suspected cerebellitis. Laboratory evaluation consisting of a blood count, hepatic function analysis and metabolic screening was normal. Light silvery-gray colored scalp hair and eyebrows with normal pattern and texture were noted (Figure 1A). Cerebrospinal fluid showed discrete pleocytosis with a predominance of mononuclear cells and also a discrete increase of proteins. FLAIR (fluidattenuated inversion-recovery) MRI of the encephalon showed lesion at the right cerebellar hemisphere with capturing contrast, and a small area of hypersignal in the supratentorial white matter (Figure 1B-D). Treatment with acyclovir was initiated and continued for 21 days. Blood and hair of this patient and his parents were collected for molecular or microscopy analyses as described in the next sections.

Two months after his discharge from the hospital, the patient started to have fever again. Another blood count showed thrombocytopenia. The child was hospitalized again and his clinical features progressed to pancytopenia, hepatosplenomegaly, fever and coma. After removal of sedative medicines, the child remained in a persistent vegetative state, with continuous fever, hepatosplenomegaly, tetraparesis, and axial hypotonia. He showed symmetrical osteotendineous reflexes and lack of the photomotor reflex, and was treated with corticoid and cyclosporine. However, he did not respond to treatment and died.

\section{Material and Methods}

\section{Hair imaging}

Hair shafts were mounted on slides with Permount (Fischer Scientific, USA), covered with a coverslip and analyzed directly and photographed on bright field microscopy using a digital camera.

\section{Peripheral blood mononuclear cells isolation}

Peripheral blood mononuclear cells (PBMC) were separated from whole heparinized blood by the Ficoll-Hypaque density-gradient technique (Hystopaque 1077, Sigma Al- 
drich, USA). Samples of cells were cultured in RPMI 1640 medium (Invitrogen, USA), supplemented with $2 \mathrm{mM}$ Lglutamine, $1.5 \mathrm{~g} / \mathrm{L}$ sodium bicarbonate, $4.5 \mathrm{~g} / \mathrm{L}$ glucose, 10 mM HEPES, and $10 \%$ fetal calf serum (FCS), in a humidified atmosphere of $5 \% \mathrm{CO}_{2}$, at $37^{\circ} \mathrm{C}$. Cultured cells were frozen in $90 \% \mathrm{FCS} / 10 \%$ dimethyl sulfoxide and stored in liquid nitrogen.

\section{Genomic DNA extraction}

DNA was extracted from PBMC by a standard phenolchloroform technique.

\section{Polymerase chain reaction amplification}

For the polymerase chain reaction (PCR) amplification of the RAB27A gene from the genomic DNA of the patient and his parents, we used the Elongase ${ }^{\circledR}$ Enzyme Mix (Invitrogen) and primers flanking coding regions of the five coding exons of the RAB27A gene (8). The coding exons are numbered 2-6 according to the reference sequence (RefSeq) gene NM_004580 (NCBI and UCSC genome browser). The sequence of the pairs of primers used to amplify these regions are: 5'TCATACAACCCGT AGACATACA3'/5'TGTTGACTTAACGATTACATTTTT3'; 5'TTGTTTTCTCTTTCACTTTG3'/5'TTTTCCCTTTCC TTCAG3'; 5'GCTGAAGGCATTGCTTGT3'/5'AGATCT CCTCCAAAACGATT3'; 5'TTTTGCATGTATTGTTCA C T GA 3 ' / 5 ' T G G C T G A G G T T T T GCT T TA 3 ' ; 5'TGTCTTCCAGAATCCCCTACT3'/5'ATGCCC ATTAATCTCTCACTGT3'.

\section{Mutation detection}

PCR products were sequenced directly using the Big DyeDeoxy terminator kit and an ABI 3100 sequencer (Applied Biosystems, USA). Sequences were aligned with the RAB27A genomic contig NT_010194.16 and human NCBI RAB27A RefSeq mRNAs.

Reverse transcription and polymerase chain reaction

Total RNA and protein were extracted simultaneously from the PBMC of the patient and his parents and from Jurkat lymphocytes using the Trizol ${ }^{\circledR}$ reagent (Invitrogen), according to the protocol suggested by the manufacturer. For reverse transcription (RT), we used the Superscript II enzyme (Invitrogen) and for PCR amplification of the target cDNA, the Elongase or Taq DNA polymerase (Invitrogen). The sequences of the pairs of primers used for amplification of RAB27A, MYO5A, and $ß$-actin cDNA fragments are: 5'GATAAGCCAGCTACAGATGCA3'/5'TAATGGGG ATGGTGAGAAGCA3'; 5'AGTCTCTGTGTCGTTCATT CG3'/5'CCTGTATGTAAACTCACGGTA3'; 5'GGCATCG TGATGGACTCCG3'/5'GCTGGAAGGTGGACAGCGA3'.

\section{Immunoblotting}

For immunoblotting, we used a mouse monoclonal antibody to human Rab27a (Transduction Laboratories, USA; catalog R52320), which recognizes a $25-\mathrm{kDa}$ polypeptide.

\section{Results}

Light microscopy analysis of the hair revealed large clumps of pigments in the hair shaft of the patient, typical of GS, in contrast with the even pigment distribution in normal hair shafts and the typical punctuating pattern seen in the hair from a $\mathrm{CHS}$ patient (Figure 1E-H). A skin biopsy could not be performed. In order to determine the mutation and to confirm the GS2 subtype, we amplified by PCR and sequenced the five exons comprising the coding region of the $R A B 27 A$ gene and part of the flanking introns (Figure 2). At least 3 sequencing runs were performed directly from the PCR product for each fragment. Good quality consensus sequences were extracted and a single nonsense mutation, a C-T transition, c.550C>T, mapping to exon 6 was found (Figure 2D). This mutation is predicted to cause a premature translation termination instead of arginine $(R)$ at position 184 of Rab27a, truncating the protein by 38 amino acid residues at the C-terminal (wild-type Rab27a is predicted to have 221 amino acid residues).

RT-PCR amplification allowed us to confirm the presence of RAB27A mRNA in RNA samples extracted from PBMC of the patient as well as of the parents (Figure 3 ), demonstrating that this mutant form of mRNA is not unstable. Since myosin-Va functions in complex with Rab27a and is the gene associated with GS1, we also checked for any abnormality in the expression of this gene. RT-PCR showed equivalent amplification of a cDNA fragment from the patient and his parents, indicating that there was probably no alteration in the expression of this gene (Figure 3). Western blot showed the detection of a $25-\mathrm{kDa}$ polypeptide, the expected apparent molecular mass for Rab27a on SDS-PAGE, for the father and the mother, but only a very faint signal for the patient (Figure 3 ). Although the predicted truncation caused by the mutation would probably shift the relative molecular mass to near $21 \mathrm{kDa}$, we did not detect any bands in a lower molecular weight range in the patient's lane. A nonspecific band ( 50 $\mathrm{kDa}$ ), which is being used here as a loading control, indicates that a lower amount of total protein was loaded in the patient lane, but this does not appear to account for the greatly diminished signal for Rab27a in the patient sample, leading to the suggestion that the mutant protein is either susceptible to proteolysis or not efficiently translated. 
Figure 1. Typical features of Griscelli syndrome. $A$, The twin patients. Note the very light silvery-gray color of the hair and eyebrows. $B-D$, FLAIR-MRI obtained from the encephalon of one of the patients, showing a hypersignal (arrows) in the right cerebellar hemisphere and in the cerebral white matter: axial sections $(B, C)$ and sagittal section (D). $E-H$, Light micrographs of the hair, showing the large clumps of pigment irregularly distributed in the hair shafts of the patient (E), in contrast with fine, well-distributed pigment in normal controls from persons with brown $(F)$ and blond $(G)$ hair, and the punctuating pattern of the pigment in a hair shaft from a Chédiak-Higashi patient $(\mathrm{H})$, who was also attended in our health service. [Color figure can be viewed in the online issue, which is available at www.interscience.wiley.com].
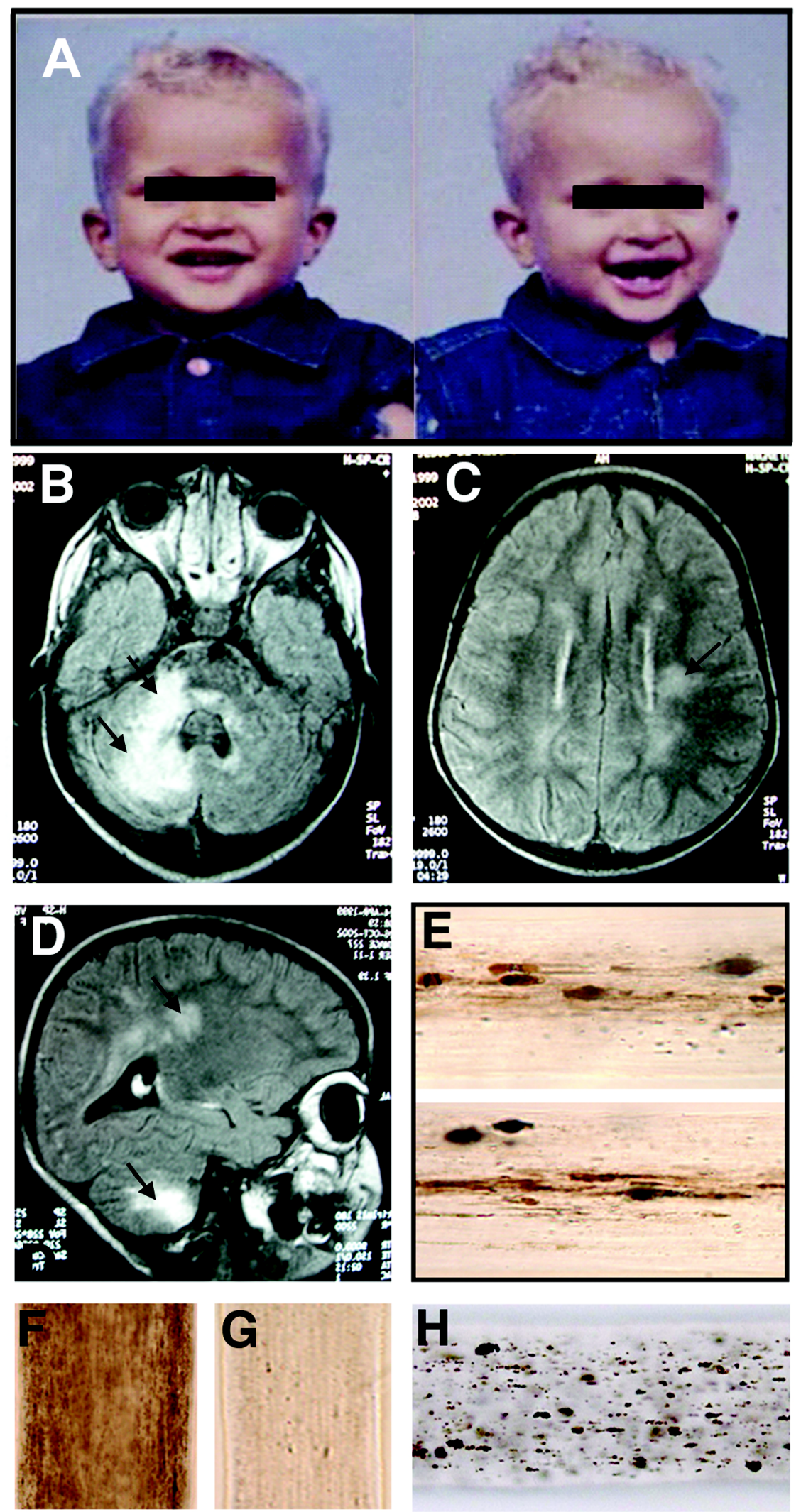

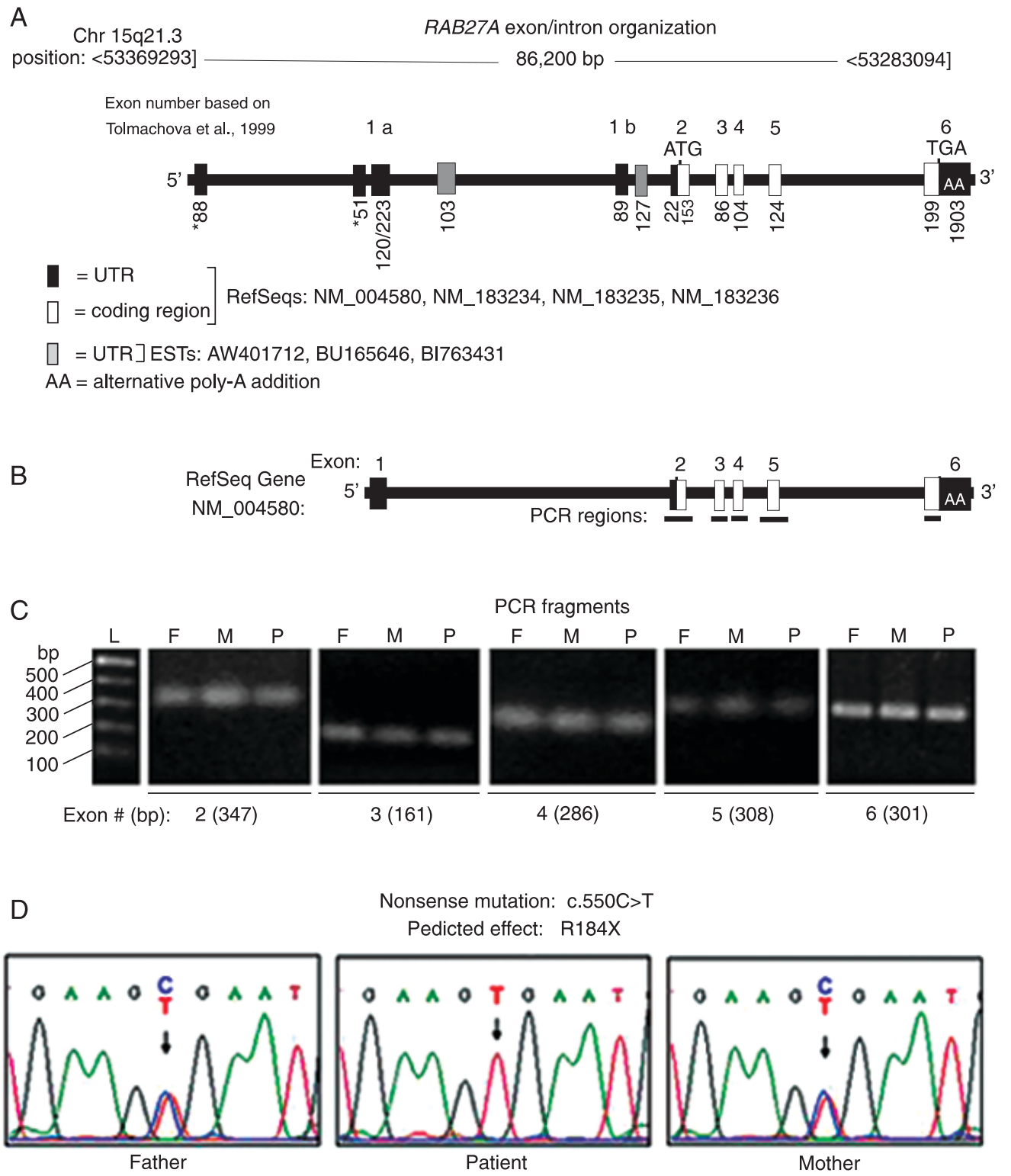

Figure 2. The RAB27A gene, PCR products and detection of a nonsense mutation. $A$, Schematic representation of the exon/intron organization of the RAB27A gene based on the indicated NCBI RefSeqs and expressed sequence tags (ESTs). Exons within the untranslated (UTR) and coding regions are represented by filled-in and empty boxes, respectively. According to four NCBI RefSeqs available, the RAB27A gene comprises 9 exons (black and empty boxes) spanning 86,200 bp within the indicated interval in the minus strand, chromosome 15q21.3 (genomic contig NT_010194). Also, additional exons (gray boxes) are supported by ESTs in the 5'UTR, or even upstream from RAB27A genomic region (not indicated; see Discussion). The coding region of 666 bp is constant among the transcript variants. Exons identified by Tolmachova et al. (22) are numbered accordingly. Exon 1a is present in all RefSeqs while the other five exons within the UTR are alternatively spliced, even though exon 1a also shows transcribed segments of alternative lengths (223 or $120 \mathrm{bp}$ ) in different mRNA sequences, suggesting alternative splicing site usage. *Indicates that 88 or 51 bp are the lengths of these exonic segments in RefSeqs NM_183235 and NM_183236, respectively, which are probably incomplete. B, Schematic of the most abundantly expressed isoform, represented by RefSeq gene NM_004580 (transcript variant 1) (27) depicting the regions amplified by PCR. C, PCR products of the indicated regions $(B)$ obtained from the genomic DNA, stained with ethidium bromide on agarose gels, for the father $(F)$, mother $(M)$ and the patient $(P)$. $L=$ length marker (ladder): O'Gene Ruler ${ }^{\mathrm{TM}}$ (Fermentas, Burlington, $\mathrm{ON}$, Canada). D, Sequence electropherograms showing the c.550C $>\mathrm{T}$ mutation (arrow) in homozygous form in the patient and heterozygous in his parents. This mutation predicts a premature translation termination instead of arginine $(R)$ at position 184 of the Rab27a protein. Color figure can be viewed in the online issue, which is available at www.interscience.wiley.com. 

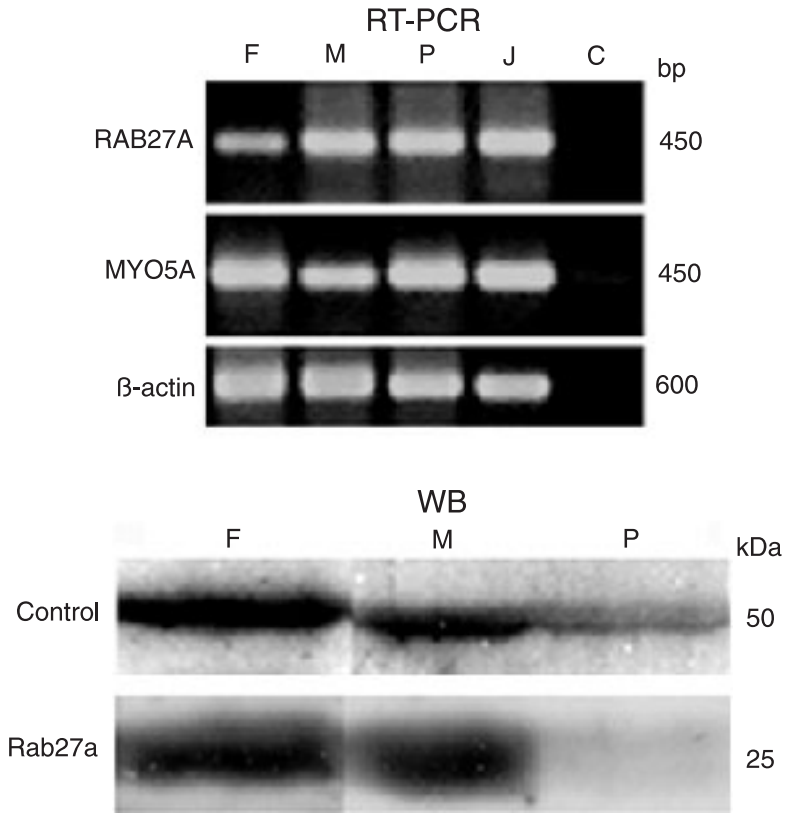

\section{Discussion}

A mutation identical to the one shown here was previously reported in two brothers from a non-consanguineous Mauritian family (8) and in an Indian child (21), but this is the first time that protein expression was analyzed for this mutation. The inability to detect a protein leads to the conclusion that Western blot can be used as a tentative rapid assay to associate the disease with $R A B 27 A$.

A total of 101 cases with the clinical and laboratory features of GS2 have been reported in the literature [see OMIM (Online Mendelian Inheritance in Man) 607624 and 603868 , and for a list of references on GS2 case reports, which have not identified the mutation and are not cited in OMIM, see our WEB resource at FMRP.USP cited in the next section]. Amongst these 101 cases, 54 GS2 patients had their mutations sequenced, totaling the occurrence of 27 different mutations in this locus associated with GS2 plus 1 heterozygous mutation not associated with this disease (Table 1). The Human Gene Mutation Database at the Institute of Medical Genetics in Cardiff (HGMDBIOBASE) resource currently refers to only 13 mutations. The exon numbering of $R A B 27 A$ is currently done in accordance to the nomenclature proposed by Tolmachova et al. (22), when two 5'UTR exons (named 1a and $1 \mathrm{~b}$ ) had been detected; however, a much higher complexity has been revealed by a large number of expressed sequences matching this locus, generating discrepancies in the literature. This led us to tentatively present an updated compilation of
Figure 3. RAB27A and MYO5A mRNA, but not the Rab27A protein, are normally expressed in peripheral blood mononuclear cells (PBMC) of the patient. Reverse transcription and polymerase chain reaction (RT-PCR) for amplification of cDNA fragments from RAB27A, MYO5A, and B-actin as control, were performed on total RNA extracted from the PBMC of the father $(F)$, the mother $(M)$, and the patient $(P)$, and the Jurkat $C D 4^{+}$ lymphoblast cell line $(\mathrm{J})$. RT using oligo-dT priming and DNase treatment were performed prior to PCR amplification. A PCR control reaction was performed on one of the RNA samples, DNase treated without previous RT (C). Western blot (WB) containing total protein extracts of PBMC from the father $(F)$, the mother $(M)$ and the patient $(P)$ immunoreacted with a monoclonal antibody to Rab27a and developed by chemiluminescence. An unspecified $50-\mathrm{kDa}$ band is used here as an internal loading control for normalization. exon/intron organization for the $R A B 27 A$ gene predicted from alignments of expressed sequences with the genomic contig (Figure 2). In addition to NM_004580 (transcript variant 1), three other RAB27A NCBI RefSeqs were assembled and annotated as transcript variants 2 to 4 , supported by full open-reading frame mRNA sequences, which shows 3 alternatively spliced exons in the 5'UTR plus an alternative splice site usage in exon $1 \mathrm{a}$, resulting in alternatively spliced regions of 223 or $120 \mathrm{bp}$ in length for this exon. Furthermore, two novel exons not included in the NCBI RefSeqs, represented by gray bars in Figure 2, are supported by expressed sequence tags (ESTs). Interestingly, there are also at least two independent ESTs (DA795745, DR156180), which support the inclusion in this gene of two novel exons located upstream from the genomic region of $R A B 27 A$ such that they overlap with the PIGB (phosphatidylinositol glycan - class B) gene, implicating in further structural or transcriptional complexity to this locus, whose relevance will require further investigation to clarify. Regardless of such mRNA diversity due to multiple alternative splices in the 5'UTR and alternative poly-A addition signals in the 3'UTR, the coding region of the gene is rather constant. $R A B 27 A$ is an easy gene to scan by sequencing due to its small size and because all detected mutations associated with GS2, except for two large deletions, are restricted either to the coding region or near splice sites.

The prognosis and treatment of GS depend on the type of the condition. GS is most commonly diagnosed between 
the ages of 4 months and 7 years (3). There is no cure for GS1 and the life of the patients depends on the severity of the neurological impairment. GS3 does not need treatment since it involves altered pigmentation only. The treatment of choice for GS2 is bone marrow transplantation (BMT), which should be done as early as possible. The case of the two monozygotic twins reported here is an example of how important it is to prepare the health care services to recognize this disease and propose effective treatment in time. In this case, the first patient died in the accelerated hemophagocytic syndrome phase more than 6 months ahead of his brother, who at that time was in perfect physical condition for a BMT. Cases of successful BMT are re- ported and immunosuppressive therapy is also used to maintain the patient stable as a palliative therapy or to induce remission until BMT (3,23-25). Bizario et al. (26) showed rescuing of cytotoxic $T$ lymphocyte activity using a retroviral vector to mediate the transfer of $R A B 27 A$ gene, opening an alternative possibility for GS2 treatment. Although it demands further studies, gene therapy may prove to be an excellent way to treat GS and other genetic immune disorders. Recent progress has also uncovered the molecular basis of other classes of familial HLH (1012), even the ones not involving pigmentation defects, improving the possibilities for early diagnosis and treatment of this large group of life-threatening diseases.

Table 1. Summary of human mutations reported in RAB27A.

\begin{tabular}{|c|c|c|c|c|c|}
\hline Mutationa & Location ${ }^{b}$ & Predicted effect & Occurrence & Origin & References \\
\hline \multirow[t]{3}{*}{ c. $550 \mathrm{C}>\mathrm{T}$} & Exon 6 & R184X & $2^{c}$ & Mauritius & 8 \\
\hline & & & 1 & India & 21 \\
\hline & & & $2^{c}$ & Brazil & Present study \\
\hline c. $217 \mathrm{~T}>\mathrm{G}$ & Exon 3 & W73G & 2 & Turkey & 8,28 \\
\hline c. $389 \mathrm{~T}>\mathrm{C}$ & Exon 5 & L130P & 1 & Turkey & 8 \\
\hline c. $454 \mathrm{G}>\mathrm{C}$ & Exon 5 & A152P & 1 & Turkey & 8 \\
\hline c. $346 \mathrm{C}>\mathrm{T}$ & Exon 5 & Q116X & 1 & Turkey & 28 \\
\hline \multirow[t]{2}{*}{ c.149delG } & Exon 2 & R50fsX84 & 11 & Turkey & $8,28,29$ \\
\hline & & & 1 & Germany & 29 \\
\hline \multirow[t]{5}{*}{ c.510delAAGCC } & Exon 6 & Q172fsX173 & 2 & Turkey & 8 \\
\hline & & & 1 & Armenia & 24 \\
\hline & & & $2^{c}$ & Turkey & 30 \\
\hline & & & 1 & Iran & 31 \\
\hline & & & 1 & Italy & 25 \\
\hline c. 154 del154-343 & Exon $3+4$ & V52fsX65 & 3 & North Africa & 8 \\
\hline c.400delAA & Exon 5 & K134fsX135 & 1 & USA & 8 \\
\hline c.51del CT & Exon 2 & S18fsX32 & 1 & Arabic & 32 \\
\hline $67.5 \mathrm{~kb}$ del & Exon $1-5$ & null & 1 & Palestine & 33 \\
\hline c. $352 C>T$ & Exon 5 & Q118X & & & \\
\hline c. $467+1 \mathrm{G}>\mathrm{C}$ & Intron 5 & G156fs & 1 & Brazil & 26 \\
\hline c. $467+1 G>C$ & Intron 5 & G156fs & 1 & Brazil & 8 \\
\hline c. $239+3 A>G$ & Intron 3 & R80fs & 1 & North Africa & 8 \\
\hline c. $259 \mathrm{G}>\mathrm{C}$ & Exon 4 & A87P & & & \\
\hline $27.8 \mathrm{~kb}$ del & Exon 2-5 & null & 1 & Germany & 29 \\
\hline c. $598 \mathrm{C}>\mathrm{T}$ & Exon 6 & $\mathrm{R} 200 \mathrm{X}$ & 1 & Asiatic & 34 \\
\hline Not shown & & & 1 & India & 35 \\
\hline c. $149 \mathrm{G}>\mathrm{C}$ & Exon 2 & Arg50fsX34 & 1 & Iran & 31 \\
\hline c. $131 \mathrm{~T}>\mathrm{C}$ & Exon 2 & Ile44Thr & 1 & Iran & 31 \\
\hline c.340delA & Exon 4 & Ile114X & 1 & Iran & 31 \\
\hline c.514delCAAGC & Exon 6 & GIn172fsX1 & 5 & Iran & 31,36 \\
\hline c. $400 A>G$ & Exon 5 & K134E & 3 & Jordan & 37 \\
\hline c. $127 \mathrm{G}>\mathrm{A}$ & Exon 2 & G43S & 1 & Afghanistan & 38 \\
\hline c. $550 \mathrm{C}>\mathrm{T}$ & Exon 6 & $\mathrm{R} 184 \mathrm{X}$ & 1 & Denmark & 38 \\
\hline c. $598 \mathrm{C}>\mathrm{T}$ & Exon 6 & $\mathrm{R} 200 \mathrm{X}$ & 1 & Denmark & 38 \\
\hline c.148-149delAGinsC & Exon 2 & R50fsX84 & $1^{d}$ & Germany & 39 \\
\hline
\end{tabular}

aNumbering is based on the coding sequence (CDS), which is constant in all 4 RAB27A transcript variants (NM_004580, NM_183234,

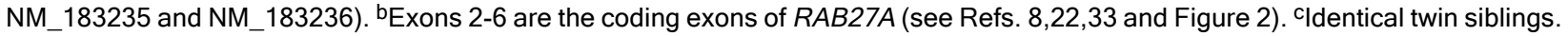
$\mathrm{fs}=$ frameshift, $\mathrm{X}=$ stop codon. ${ }^{\text {dPatient }}$ with Hermansky-Pudlack syndrome carrying this heterozygous mutation in $R A B 27 A$, as well as his healthy father. 


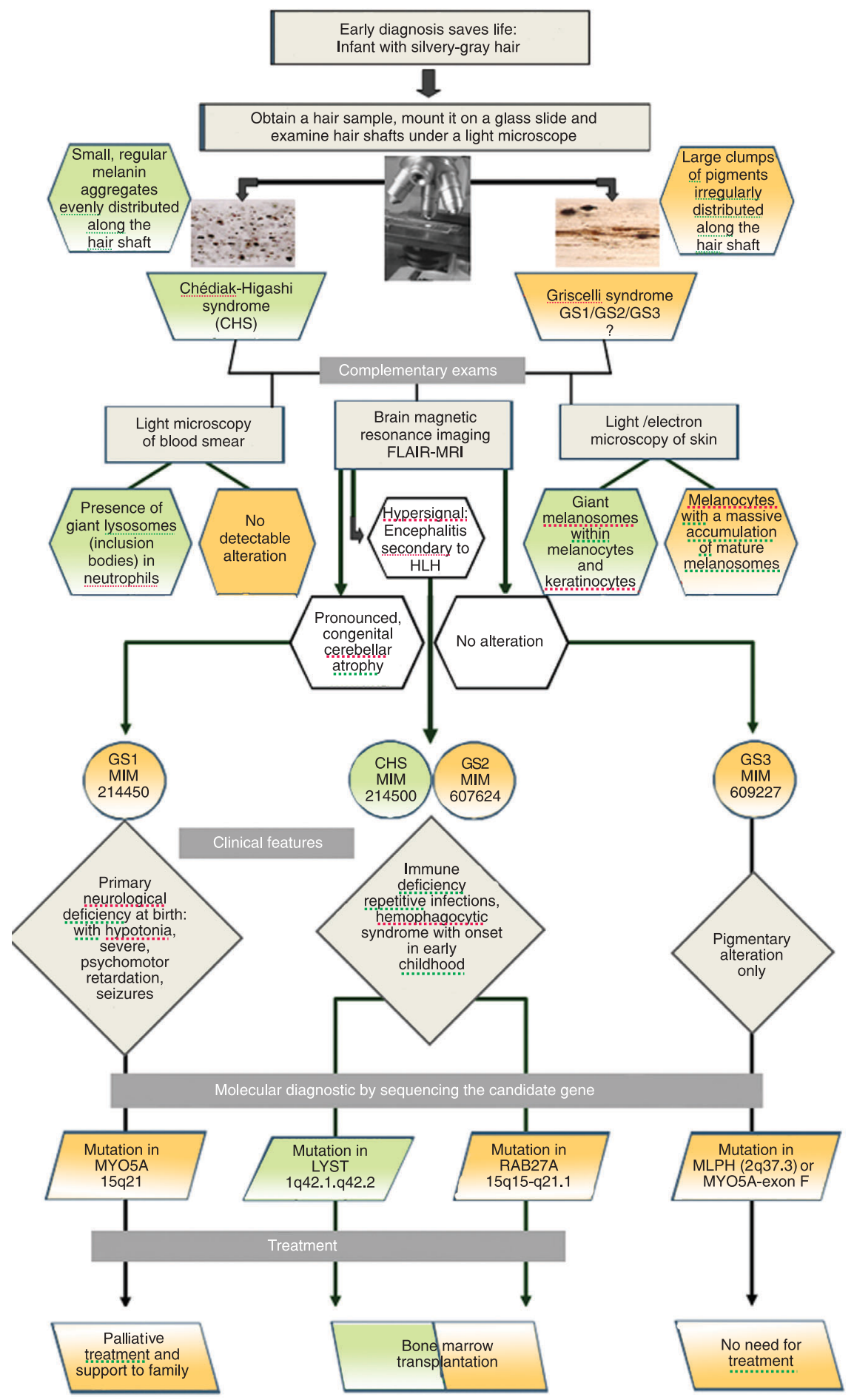

Figure 4. A flow chart to guide the early diagnosis of Griscelli (GS) and Chédiak-Higashi syndromes (CHS). The flow chart summarizes the steps to follow after signs of silvery-gray hair are detected in an infant. The steps include examinations required for differential and complementary diagnosis and point towards the candidate gene for sequencing. Molecular diagnosis is then mandatory to provide information necessary for the physician to adopt effective treatment when available. Bone marrow transplantation offers the possibility of effective treatment for CHS and GS2 patients. FLAIR = fluid-attenuated inversion-recovery; HLH = hemophagocytic lymphohistiocytosis. 
Finally, as shown in Figure 4, a flow chart was created to summarize the steps to follow once signs of silvery-gray hair are detected in an infant. GS and CHS can be promptly distinguished by light microscopy of hair shafts, which is very easy to perform. Complementary exams, such as light microscopy of blood smear and of a skin biopsy, may also be adopted in searching for the presence of giant lysosomes/endosomes (inclusion bodies) in leukocytes or giant melanosomes in melanocytes as characteristics of CHS and, conversely, the absence of giant granules in leukocytes but the presence of a large accumulation of normal mature melanosomes within the melanocytes are typical features of GS. Subsequently, FLAIR-MRI of the brain might also be helpful in the interpretation of the degree of neurological defects. Primary neurological deficiency marked by profound, congenital cerebellar atrophy is associated to GS1 (Elejalde) (27), and secondary neurological damage involving the white matter, due to leukocyte infiltration that occurs during $\mathrm{HLH}$ manifestation, is associated with GS2 and CHS. Finally, sequencing the candidate gene is mandatory to identify the molecular basis of the disease, supporting physicians to adopt effective treatment, which is available for GS2 and CHS patients as BMT. GS1 patients should receive family support and palliative health care and GS3 patients have no need for treatment. Concluding, all infants with silvery-gray hair should be evaluated before any complicated symptoms appear. The urgency of an early diagnosis is justified by the possibility of saving lives in the case of GS2 and CHS. Thus, a health program directed at the neonatal diagnosis of these diseases should be implemented in most countries without much effort.

\section{Acknowledgments}

We are especially grateful to the family members for their cooperation with this study and effort in seeking the causes of the fatal disease that affected their children. We also thank Dr. Débora Borges do Amaral who helped treat the patients during their illness. Finally, we are thankful to Silmara Reis Banzi and Benedita Oliveira Souza for their technical assistance.

\section{Web Resources}

$\mathrm{NCBI}=$ http://www.ncbi.nlm.nih.gov http://www.ncbi.nlm.nih.gov/entrez/query.fcgi?db=gene\&cmd=Retrieve\&dopt=full_report\&list_uids=5873

UCSC Genome Browser = http://genome.ucsc.edu/cgi-bin/hgBlat

Online Mendelian Inheritance in Man (OMIM) = http://www.ncbi.nlm.nih.gov/entrez/query.fcgi?db=OMIM

The Human Gene Mutation Database at the Institute of Medical Genetics in Cardiff(HGMD-BIOBASE)=http://www.hgmd.cf.ac.uk/ac/gene.php?gene=RAB27A

Primary Immunodeficiency Mutation Databases (IDbases) = http://bioinf.uta.fi/IDbases (http://bioinf.uta.fi/RAB27Abase)

Reference list of clinical reports on Griscelli Syndrome-2 at FMRP.USP = http://morpheus.fmrp.usp.br/bcmcitoesqueleto/gs_cases.html

\section{References}

1. Griscelli C, Durandy A, Guy-Grand D, Daguillard F, Herzog C, Prunieras M. A syndrome associating partial albinism and immunodeficiency. Am J Med 1978; 65: 691-702.

2. Barak $\mathrm{Y}$, Nir E. Chediak-Higashi syndrome. Am J Pediatr Hematol Oncol 1987; 9: 42-55.

3. Klein C, Philippe N, Le Deist F, Fraitag S, Prost C, Durandy A, et al. Partial albinism with immunodeficiency (Griscelli syndrome). J Pediatr 1994; 125: 886-895.

4. Pastural E, Barrat FJ, Dufourcq-Lagelouse R, Certain S, Sanal O, Jabado N, et al. Griscelli disease maps to chromosome $15 q 21$ and is associated with mutations in the myosin-Va gene. Nat Genet 1997; 16: 289-292.

5. Krendel M, Mooseker MS. Myosins: tails (and heads) of functional diversity. Physiology 2005; 20: 239-251.

6. Langford GM, Molyneaux BJ. Myosin V in the brain: mutations lead to neurological defects. Brain Res Brain Res Rev 1998; 28: 1-8.

7. Larson RE. Myosin-V: a class of unconventional molecular motors. Braz J Med Biol Res 1996; 29: 309-318.

8. Menasche G, Pastural E, Feldmann J, Certain S, Ersoy F,
Dupuis S, et al. Mutations in RAB27A cause Griscelli syndrome associated with haemophagocytic syndrome. Nat Genet 2000; 25: 173-176.

9. Pastural E, Ersoy F, Yalman N, Wulffraat N, Grillo E, Ozkinay $F$, et al. Two genes are responsible for Griscelli syndrome at the same 15q21 locus. Genomics 2000; 63: 299-306.

10. Janka G, zur Stadt U. Familial and acquired hemophagocytic lymphohistiocytosis. Hematol Am Soc Hematol Educ Program 2005; 82-88.

11. Menasche G, Feldmann J, Fischer A, de Saint Basile G. Primary hemophagocytic syndromes point to a direct link between lymphocyte cytotoxicity and homeostasis. Immunol Rev 2005; 203: 165-179.

12. Stinchcombe J, Bossi G, Griffiths GM. Linking albinism and immunity: the secrets of secretory lysosomes. Science 2004; 305: 55-59.

13. Henter JI, Elinder G, Ost A. Diagnostic guidelines for hemophagocytic lymphohistiocytosis. The FHL Study Group of the Histiocyte Society. Semin Oncol 1991; 18: 29-33. 
14. Barral DC, Seabra MC. The melanosome as a model to study organelle motility in mammals. Pigment Cell Res 2004; 17: $111-118$.

15. Fukuda M. Versatile role of Rab27 in membrane trafficking: focus on the Rab27 effector families. J Biochem 2005; 137: 9-16.

16. Izumi T, Gomi H, Kasai K, Mizutani S, Torii S. The roles of Rab27 and its effectors in the regulated secretory pathways. Cell Struct Funct 2003; 28: 465-474.

17. Olkkonen VM, Ikonen E. When intracellular logistics fails genetic defects in membrane trafficking. J Cell Sci 2006; 119: 5031-5045.

18. Menasche G, Ho CH, Sanal O, Feldmann J, Tezcan I, Ersoy $F$, et al. Griscelli syndrome restricted to hypopigmentation results from a melanophilin defect (GS3) or a MYO5A Fexon deletion (GS1). J Clin Invest 2003; 112: 450-456.

19. Wu XS, Rao K, Zhang H, Wang F, Sellers JR, Matesic LE, et al. Identification of an organelle receptor for myosin-Va. Nat Cell Biol 2002; 4: 271-278.

20. Feldmann J, Callebaut I, Raposo G, Certain S, Bacq D, Dumont $C$, et al. Munc13-4 is essential for cytolytic granules fusion and is mutated in a form of familial hemophagocytic lymphohistiocytosis (FHL3). Cell 2003; 115: 461-473.

21. Sheela SR, Latha M, Injody SJ. Griscelli syndrome: Rab 27a mutation. Indian Pediatr 2004; 41: 944-947.

22. Tolmachova T, Ramalho JS, Anant JS, Schultz RA, Huxley $\mathrm{CM}$, Seabra MC. Cloning, mapping and characterization of the human RAB27A gene. Gene 1999; 239: 109-116.

23. Blanche S, Caniglia M, Girault D, Landman J, Griscelli C, Fischer A. Treatment of hemophagocytic lymphohistiocytosis with chemotherapy and bone marrow transplantation: a single-center study of 22 cases. Blood 1991; 78: 51-54.

24. Schuster F, Stachel DK, Schmid I, Baumeister FA, Graubner UB, Weiss M, et al. Griscelli syndrome: report of the first peripheral blood stem cell transplant and the role of mutations in the RAB27A gene as an indication for BMT. Bone Marrow Transplant 2001; 28: 409-412.

25. Arico $M$, Zecca $M$, Santoro $N$, Caselli $D$, Maccario $R$, Danesino C, et al. Successful treatment of Griscelli syndrome with unrelated donor allogeneic hematopoietic stem cell transplantation. Bone Marrow Transplant 2002; 29: 995998.

26. Bizario JC, Feldmann J, Castro FA, Menasche G, Jacob $\mathrm{CM}$, Cristofani L, et al. Griscelli syndrome: characterization of a new mutation and rescue of T-cytotoxic activity by retroviral transfer of RAB27A gene. J Clin Immunol 2004; 24: $397-410$

27. Sanal O, Yel L, Kucukali T, Gilbert-Barnes E, Tardieu M, Texcan I, et al. An allelic variant of Griscelli disease: presentation with severe hypotonia, mental-motor retardation, and hypopigmentation consistent with Elejalde syndrome (neu- roectodermal melanolysosomal disorder). J Neurol 2000; 247: 570-572.

28. Sanal O, Ersoy F, Tezcan I, Metin A, Yel L, Menasche G, et al. Griscelli disease: genotype-phenotype correlation in an array of clinical heterogeneity. J Clin Immunol 2002; 22: 237-243.

29. zur Stadt U, Beutel K, Kolberg S, Schneppenheim R, Kabisch $H$, Janka $G$, et al. Mutation spectrum in children with primary hemophagocytic lymphohistiocytosis: molecular and functional analyses of PRF1, UNC13D, STX11, and RAB27A. Hum Mutat 2006; 27: 62-68.

30. Sarper N, Ipek IO, Ceran O, Karaman S, Bozaykut A, Inan $S$. A rare syndrome in the differential diagnosis of hepatosplenomegaly and pancytopenia: report of identical twins with Griscelli disease. Ann Trop Paediatr 2003; 23: 69-73.

31. Mamishi S, Modarressi MH, Pourakbari B, Tamizifar B, Mahjoub F, Fahimzad A, et al. Analysis of RAB27A gene in Griscelli syndrome type 2: novel mutations including a deletion hotspot. J Clin Immunol 2008; 28: 384-389.

32. Aksu G, Kutukculer N, Genel F, Vergin C, Omowaire B. Griscelli syndrome without hemophagocytosis in an elevenyear-old girl: expanding the phenotypic spectrum of Rab27A mutations in humans. Am J Med Genet A 2003; 116A: 329333.

33. Anikster $Y$, Huizing $M$, Anderson PD, Fitzpatrick DL, Klar A, Gross-Kieselstein E, et al. Evidence that Griscelli syndrome with neurological involvement is caused by mutations in RAB27A, not MYO5A. Am J Hum Genet 2002; 71: 407-414.

34. Rajadhyax M, Neti G, Crow Y, Tyagi A. Neurological presentation of Griscelli syndrome: obstructive hydrocephalus without haematological abnormalities or organomegaly. Brain Dev 2007; 29: 247-250.

35. Aslan D, Sari S, Derinoz O, Dalgic B. Griscelli syndrome: description of a case with Rab27A mutation. Pediatr Hematol Oncol 2006; 23: 255-261.

36. Onay H, Balkan C, Cogulu O, Aydinok Y, Karapinar DY, Ozkinay F. A further Turkish case of Griscelli syndrome with new RAB27A mutation. J Am Acad Dermatol 2008; 58: S115-S116.

37. Masri A, Bakri FG, Al-Hussaini M, Al-Hadidy A, Hirzallah R, de Saint Basile G, et al. Griscelli syndrome type 2: a rare and lethal disorder. J Child Neurol 2008; 23: 964-967.

38. Westbroek W, Tuchman M, Tinloy B, De Wever O, Vilboux $\mathrm{T}$, Hertz JM, et al. A novel missense mutation (G43S) in the switch I region of Rab27A causing Griscelli syndrome. Mol Genet Metab 2008; 94: 248-254.

39. Enders A, Zieger B, Schwarz K, Yoshimi A, Speckmann C, Knoepfle EM, et al. Lethal hemophagocytic lymphohistiocytosis in Hermansky-Pudlak syndrome type II. Blood 2006; 108: 81-87. 